\title{
Growth hormone-releasing peptide-biotin conjugate stimulates myocytes differentiation through insulin-like growth factor-1 and collagen type I
}

\author{
Chae Jin Lim ${ }^{1,3}$, Jung Eun Jeon ${ }^{2}$, Se Kyoo Jeong ${ }^{2}$, Seok Jeong Yoon ${ }^{3}$, Seon Deok Kwon ${ }^{3}$, Jina Lim ${ }^{3}$, Keedon Park ${ }^{3}$, \\ Dae Yong Kim ${ }^{4}$, Jeong Keun Ahn ${ }^{1, *}$ E Bong-Woo Kim ${ }^{5, *}$ \\ ${ }^{1}$ Department of Microbiology and Molecular Biology, School of Bioscience and Biotechnology, Chungnam National University, Daejeon \\ 34134, ${ }^{2}$ CRID Center, NeoPharm Co., Ltd., Daejeon 34037, ${ }^{3}$ Peptide R\&D Center, Incospharm Corporation, Daejeon 34141, Departments \\ of ${ }^{4}$ Pharmaceutical Science and Engineering, ${ }^{5}$ Cosmetic Science \& Technology, Seowon University, Cheongju 28674, Korea
}

\begin{abstract}
Based on the potential beneficial effects of growth hormone releasing peptide (GHRP)-6 on muscle functions, a newly synthesized GHRP-6-biotin conjugate was tested on cultured myoblast cells. Increased expression of myogenic marker proteins was observed in GHRP-6-biotin conjugate-treated cells. Additionally, increased expression levels of insulin-like growth factor-1 and collagen type I were observed. Furthermore, GHRP6-biotin conjugate-treated cells showed increased metabolic activity, as indicated by increased concentrations of energy metabolites, such as ATP and lactate, and increased enzymatic activity of lactate dehydrogenase and creatine kinase. Finally, binding protein analysis suggested few candidate proteins, including desmin, actin, and zinc finger protein 691 as potential targets for GHRP6-biotin conjugate action. These results suggest that the newly synthesized GHRP-6-biotin conjugate has myogenic stimulating activity through, at least in part, by stimulating collagen type I synthesis and several key proteins. Practical applications of the GHRP-6-biotin conjugate could include improving muscle condition. [BMB Reports 2015; 48(9): 501-506]
\end{abstract}

\section{INTRODUCTION}

The importance of circulating hormones in the aging process has been discussed in various reports (1). Clinical trials have used growth hormone $(\mathrm{GH})$ to investigate the effects of the

*Corresponding authors. Jeong Keun Ahn, Tel: +82-42-821-6418; Fax: +82-42-822-7367; E-mail: jkahn@cnu.ac.kr; Bong-Woo Kim, Tel: +82-43-299-8493; Fax: +82-43-299-8470; E-mail: kbw@seowon.ac.kr

http://dx.doi.org/10.5483/BMBRep.2015.48.9.258

Received 4 December 2014, Revised 18 December 2014, Accepted 22 January 2015

Keywords: Biotin, Collagen, Growth-hormone releasing peptide, Insulin-like growth factor, Myogenesis hormone in preventing the aging process and improving aging symptoms. Virtually all tissues in the human body are responsive to $\mathrm{GH}$ and $\mathrm{GH}$-involved functions may be impaired by age-related downregulation of $\mathrm{GH}$ expression (2). Some studies have used $\mathrm{GH}$ secretagogues $(\mathrm{GHS})$, peptide and non-peptide compounds that stimulate the secretion of $\mathrm{GH}$, to modulate $\mathrm{GH}$ secretion (3). One of the most potent compounds, $\mathrm{GH}$ releasing peptide (GHRP)-6, stimulates $\mathrm{GH}$ release via a unique pathway independent of $\mathrm{GH}$ releasing hormone (GHRH) (4). Efforts to develop a small molecule with $\mathrm{GH}$ releasing activity, most of which were based on peptidomimetic approaches to GHRP-6, have resulted in a few preclinical candidate compounds $(3,5)$.

The positive effects of GHS on skin, in part due to increased collagen synthesis, highlight the possible cosmetic application of GHRP-6 and its derivatives (1). However, insufficient stability of topical formulations and low bioavailability, due to low permeability of peptide compounds via the skin, make them impractical for topical application. Recently, we reported the use of a GHRP-6 derivative as a cosmetic ingredient. To improve the permeation of GHRP-6 through skin as well as to improve stability in the formulation, several GHRP- 6 derivatives conjugated with biotin (vitamin B7) were synthesized and their effects on skin-derived cells were investigated. Significant increases in collagen synthesis were observed with select GHRP-6 biotin conjugate compounds. In addition to cosmetics, effects of $\mathrm{GH}$ on muscle formation through stimulation of collagen synthesis are also well-known. Studies have shown that certain genes involved in myocyte differentiation, such as myogenin, MRF4, and MEF2C, are regulated in part by GH (6). Based on these results, in this study, we investigated the effects of a GHRP-6-biotin conjugate compound on myocyte differentiation. We show here stimulation of myogenesis via application of a GHRP-6-biotin conjugate compound, as indicated by increased expression of myogenesis marker proteins and collagen synthesis. Further investigation into the underlying signaling pathways revealed the potential involvement structural proteins, such as desmin and actin.

ISSN: 1976-670X (electronic edition)

Copyright (c) 2015 by the The Korean Society for Biochemistry and Molecular Biology

(c) This is an open-access article distributed under the terms of the Creative Commons Attribution Non-Commercial License (http://creativecommons.org/licenses/by-nc/3.0) which permits unrestricted non-commercial use, distribution, and reproduction in any medium, provided the original work is properly cited. 


\section{RESULTS}

\section{GHRP-6-biotin conjugate stimulated differentiation of cultured myoblasts}

Synthesis of the GHRP-6 hexapeptide (His-(D-Trp)-Ala-Trp(D-Phe)-Lys-NH2)-biotin conjugate was achieved by linking the carboxyl group of biotin with an amine group, in either the histidine residue at the $\mathrm{N}$-terminal or the lysinamide residue at the C-terminal of GHRP-6 by a solid-phase peptide synthesis method. A preliminary in vitro cytotoxicity evaluation of the two conjugate forms showed that the lysinamide-biotin conjugate was more cytotoxic than the histidine-biotin conjugate form (data not shown). For further evaluation, the histidine-biotin conjugate form (conventional name: Myotide) was chosen and the biological activity was assessed using cultured myocytes and compared with the native GHRP- 6 and biotin.

To investigate the effects of the GHRP-6-biotin conjugate on the differentiation of cultured myoblasts, C2C12 cells were treated with $50 \mu \mathrm{M}$ GHRP-6-biotin conjugate and expression of myogenic differentiation marker proteins, myosin heavy chain I (MyHC I), myogenin, MG53 (mitsugumin 53), and cav-
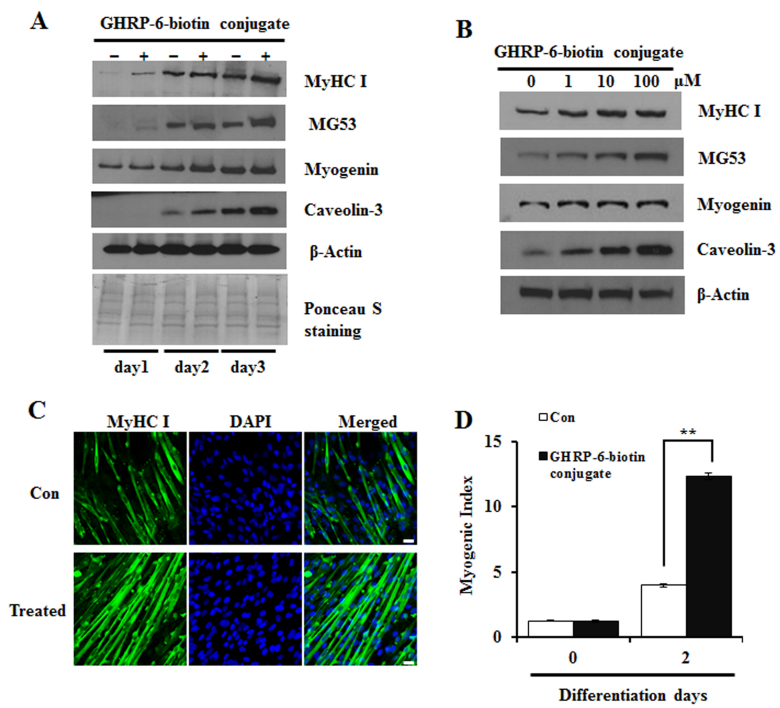

Fig. 1. Effects of a newly synthesized GHRP-6-biotin conjugate on C2C12 myocytes differentiation. (A) Confluent myoblasts were incubated for the indicated period of time with $(+)$ or without $(-)$ $50 \mu \mathrm{M}$ GHRP-6-biotin conjugates. Whole-cell lysate was analyzed by immunoblotting with anti-myosin heavy chain I (MyHC I), myogenin, MG53, and caveolin-3. $\beta$-Actin and Ponceau S staining were used as a loading control. (B) $\mathrm{C} 2 \mathrm{C} 12$ myoblasts were differentiated for $48 \mathrm{~h}$ with the indicated concentrations of GHRP-6-biotin conjugates. Equally loading of protein was checked by comparison with $\beta$-actin. These experiments were performed independently three times. Myogenesis was monitored using MyHC I immunofluorescence and DAPI (C), the myogenic index (D). The myogenic index was determined by counting the number of the nuclei in MyHC I-positive cells. All data are presented as means \pm SE. $t$-test. $* * P<0.01$ eolin-3, were quantified by Western blotting (7). As shown in Figs. $1 \mathrm{~A}$ and $\mathrm{S} 1$, treatment with the GHRP-6-biotin conjugate increased the expression of all measured proteins up to day 3. Furthermore, a dose-dependent increase in protein expression was also observed after $48 \mathrm{~h}$ of treatment (Figs. 1B, S2). As shown in Figs. $1 \mathrm{C}$ and $\mathrm{S} 3$, the nuclei number of MyHC-positive cells increased $\sim 3$-fold in 3-day-differentiated myotubes and satellite cells. Treatment with biotin or GHRP-6 alone did not induce significant change in myogenesis, suggesting that the conjugated compound may stimulate signaling pathway(s) different from those that are affected by single-compound treatment (Fig. S4). Further investigations into the underlying pathways induced by single and conjugate compounds are currently underway.

\section{GHRP-6-biotin conjugate induced IGF-1 expression and collagen synthesis}

Prior studies have suggested a potential relationship between GHRP-6 and insulin-like growth factor-1 (IGF-1) (8). Thus, we next investigated the effects of the GHRP-6-biotin conjugate on IGF-1 expression. As shown in Fig. 2A, treatment with the
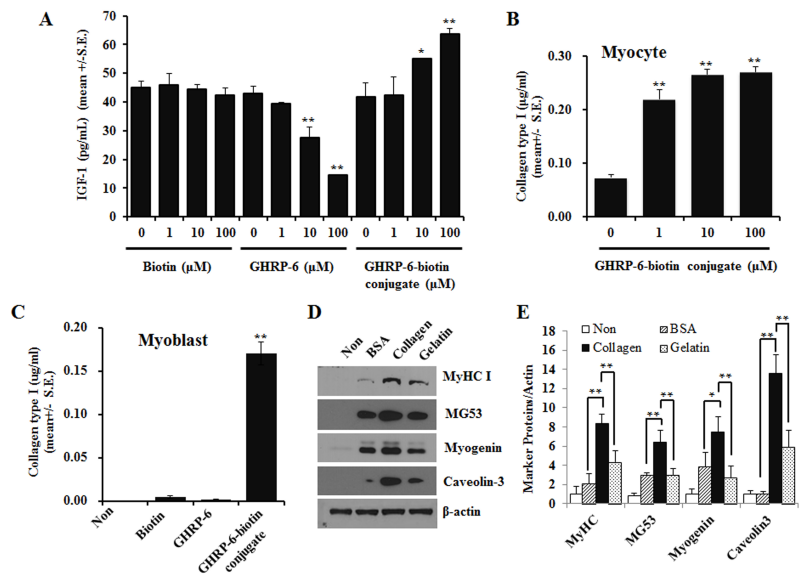

Fig. 2. Effects of GHRP-6-biotin conjugate on the secretion of IGF-1 and the production of collagen type I in $\mathrm{C} 2 \mathrm{C} 12$ myocytes. (A) IGF-1 levels in differentiation medium-cultured C2C12 cell-conditioned medium were measured as described in the Methods. C2C12 myoblasts were differentiated for $24 \mathrm{~h}$ in GHRP-6-biotin conjugates, biotin, and GHRP-6-containing differentiation medium. (B) Confluent C2C12 myoblasts were incubated for $24 \mathrm{~h}$ with the indicated concentrations of the GHRP-6-biotin conjugates in differentiation medium. Collagen I levels in the medium were analyzed with a collagen type I ELISA assay. (C) Confluent C2C12 myoblasts were incubated for $24 \mathrm{~h}$ with $50 \mu \mathrm{M}$ biotin, $50 \mu \mathrm{M}$ GHRP-6, 50 $\mu \mathrm{M}$ GHRP-6-biotin conjugates, and collagen I levels in medium were measured. (D) Confluent $\mathrm{C} 2 \mathrm{C} 12$ myoblasts were differentiated for $24 \mathrm{~h}$ in culture dish coated with collagen I, gelatin, and BSA and their differentiation was analyzed by immunoblotting with specific antibodies. (E) The ratio of myogenic markers/actin was analyzed statistically with three independent experiments. All data are shown as means \pm SE. $t$-test and analysis of variance. ${ }^{*} P<0.05$ and $* * P<0.01$. 
GHRP-6-biotin conjugate compound increased IGF-1 expression in a dose-dependent manner up to $100 \mu \mathrm{M}$. However, biotin did not induce any significant changes at the concentrations tested and treatment with GHRP-6 downregulated the expression of IGF-I in cultured myoblast cells, consistent with the results in Fig. S4.

Studies have also reported on the importance of collagen in myocyte differentiation. To investigate whether the collagen is also involved in myogenic differentiation induced by the GHRP-6 biotin conjugate, we monitored collagen type I content levels $24 \mathrm{~h}$ post treatment in myocytes. The results showed that collagen type I protein quantity in conjugate cultured medium and intracellular collagen production increased in a dose-dependent manner (Fig. 2B). Preliminary experiments with human skin fibroblasts also showed increased expression of collagen 1 with the GHRP-6-biotin conjugate compound treatment (data not shown). Treatment with biotin or GHRP-6 alone did not affect collagen type I production in cultured $\mathrm{C} 2 \mathrm{C} 12$ myoblasts (Fig. 2C). To clarify whether the increased collagen production directly mediated myogenic differentiation of $\mathrm{C} 2 \mathrm{C} 12$ cells, effects of extracellular matrix protein-coated plates on cellular responses were tested. Cells incubated using collagen type l-coated plates showed the highest expression levels of myogenic marker proteins (Fig. 2D, E).

GHRP-6 biotin conjugate increases the energy metabolites for muscle function

To further investigate the effects of the GHRP-6-biotin con-
A

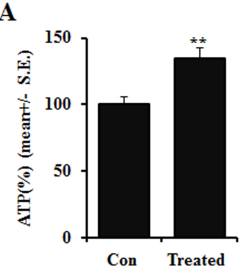

D

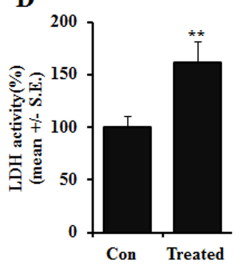

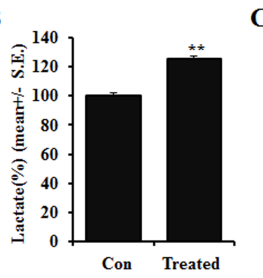
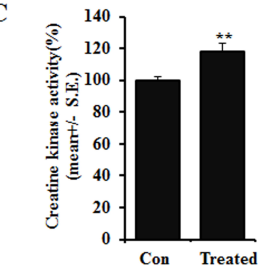

$\mathbf{E}$

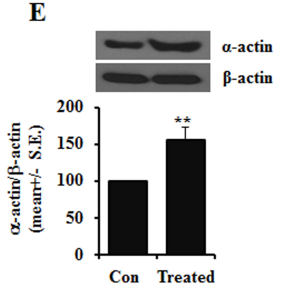

Fig. 3. Increase in cell metabolites with the GHRP-6-biotin conjugate in $\mathrm{C} 2 \mathrm{C} 12$ myocytes. Fully differentiated C2C12 myocytes were treated with $100 \mu \mathrm{M}$ GHRP-6-biotin conjugates. Intracellular energy metabolites, ATP (A) and lactate (B) were measured in whole-cell lysates. Creatine kinase activity (C) and lactate dehydrogenase activity (D) were also assessed. (E) Expression ratio of alpha-actin vs. beta-actin was measured by immunoblot. Lower panel; densitometric analysis result. All data are shown as means \pm SE. $t$-test. $* * P<0.01$. jugate at the cellular level, changes in cytosolic ATP, lactate concentrations, enzymatic activities of creatine kinase (CK), and lactate dehydrogenase (LDH) were measured. Treatment with the GHRP-6-biotin conjugate resulted in increased cytosolic ATP and lactate concentrations, and increased activity of both $\mathrm{CK}$ and LDH (Fig. 3). As shown in Fig. 3E, skeletal $\alpha$-actin protein expression, which is closely related to muscle contraction was increased significantly with GHRP-6-biotin treatment. Together, these data suggest that the GHRP-6-biotin conjugate may improve energy metabolism, which is important for muscular function, by stimulating production of energy-rich products and increasing skeletal $\alpha$-actin expression.

\section{Identification of binding partners of the GHRP-6-biotin conjugate}

To better understand the specificity of GHRP-6-biotin conjugate's effects on myoblasts, we investigated the involvement of possible binding partners for the GHRP-6-biotin conjugate in myoblasts. To explore potential candidate proteins as binding partners, co-precipitated proteins were analyzed by MALDI-TOF. Our results identified desmin, actin, and zinc finger protein 691 as possible binding partners (Fig. 4, Table S1). While the important role of desmin and actin for forming the intermediate filaments between adjacent myofibrils and cytoskeleton are well accepted, the role of zinc finger protein 691 as a transcription factor is not yet known and needs further investigation. Quantitative enzyme-linked immunosorbent assays
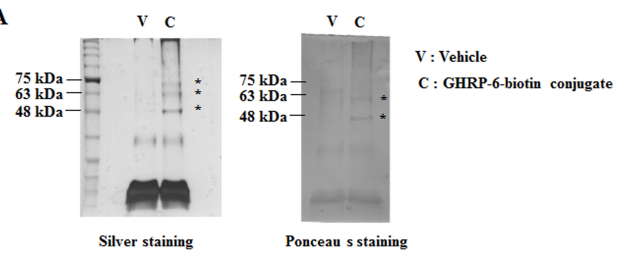

B
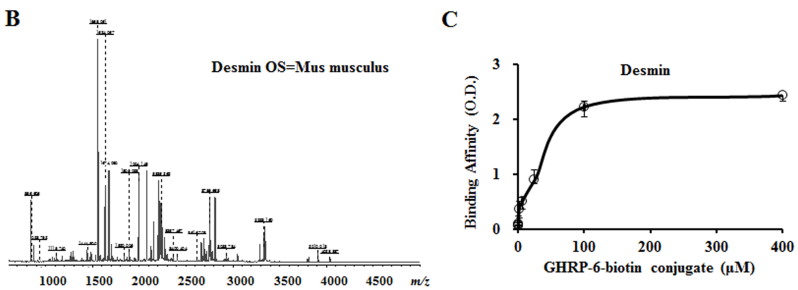

Fig. 4. Identification of GHRP-6-biotin conjugate binding proteins in $\mathrm{C} 2 \mathrm{C} 12$ myocytes. (A) Confluent $\mathrm{C} 2 \mathrm{C} 12$ myoblasts were differentiated for $24 \mathrm{~h}$ and treated with $50 \mu \mathrm{M}$ GHRP6-biotin conjugates for $1 \mathrm{~h}$. Whole-cell lysates were precipitated with immobilized streptavidin-agarose beads after cross-linking for 15 min with disuccinimidyl suberate (DSS). The precipitates were resolved by SDS-PAGE and binding partners of GHRP-6-biotin conjugates were analyzed by silver staining or Ponceau $S$ staining. (B) MS/MS spectra of desmin protein isolated from GHRP-6-biotin conjugateproteins analysis. (C) Binding of GHRP-6-biotin conjugates with desmin using a sandwich ELISA, described in the Methods. 
(ELISAs) revealed that the GHRP-6-biotin conjugate interacted directly with desmin in a dose-dependent manner (Fig. 4C).

\section{DISCUSSION}

Since the discovery of the first potent growth hormone $(\mathrm{GH})$ releasing hexapeptide, $\mathrm{GH}$ releasing peptide (GHRP)-6, many studies have sought to develop more potent and less toxic $\mathrm{GH}$ secretagogues $(3,9)$. Therapeutic benefits of GHRP-6 have been reported in various diseases, including type 1 diabetes (10), age-dependent cerebellar cell death (8), and acute myocardial infarction (11). Recently, the intranasal delivery of GHRPs has been introduced (12) and the development of topical formulations for peptides has also been reported (13).

Myogenic differentiation for muscle formation is a tightly regulated process, involving cell cycle withdrawal, fusion of myoblast cells into multinucleated myotubes and subsequent differentiation and expression of myogenic regulatory factors, including MyoD and Myf5 (14-16). Genes controlling myogenic differentiation are exquisitely regulated by hormones and growth factors (17). Among these growth factors, the insulin-like growth factors (IGFs) control myoblast proliferation, myogenic differentiation, and skeletal muscle hypertrophy (18). Previous studies have also suggested that systemic administration of GHRP-6 may increase expression of both IGF-1 mRNA and protein levels in various organs, including skeletal muscle, cardiac muscle, brain, and hypothalamus $(19,20)$. GHRP-6 increased IGF-1 mRNA levels in the cerebellum of aged rats (8) and GHRP-6 also stimulated IGF-1 mRNA expression in RCA-6 cells (20). However, whether the effect of GHRPs in muscle differentiation and development is mediated through IGF-1 remains unclear. GHRP-6 did not affect plasma IGF-1 levels or IGF-1 mRNA levels in intact hearts and the myocardial IGF-1 mRNA level was not enhanced by GHRP-6 treatment (11). In this study, we showed that GHRP-6 downregulated the expression of IGF-1 in myoblasts and inhibited myocyte differentiation (Fig. S4). However, treatment with the GHRP-6-biotin conjugate induced myogenesis and increased IGF-1 expression, suggesting that conjugation of biotin with GHRP-6 changes the biological properties of GHRP-6. While further investigation is needed, a change in the anti-oxidant properties of GHRP- 6 by conjugation with biotin may be responsible for the difference seen in IGF-1 expression inducing activity.

In addition to upregulating IGF-1 expression, the GHRP-6 biotin conjugate treatment also stimulated the synthesis of collagen type I proteins in cultured $\mathrm{C} 2 \mathrm{C} 12$ cells. While the exact role of extracellular matrix molecules in myogenesis is not yet fully understood, previous studies have reported that collagen may be involved in satellite cell self-renewal, muscle regeneration, muscle differentiation, and wound healing. Recently, Zhou et al reported that collagen synthesis significantly increases during wound healing in muscle tissue after surgery (21). Additionally, collagen IV knockout mice $\left(\right.$ Col6a $1^{-1-}$ ) show impaired muscle regeneration with satellite cell defects. Restoration of collagen IV synthesis rescued the self-renewal capability of the satellite cells and maintained muscle structure (22). Moreover, studies have also reported that integrin/collagen mediates the myogenesis process by regulating myogenic gene expression and myoblast fusion $(23,24)$. Given this background, collagen synthesis may play a critical role in muscle differentiation and regeneration.

In this study, we showed that treatment with the GHRP-6-biotin conjugate stimulated myogenic differentiation. Furthermore, this differentiation was mediated by collagen synthesis through, at least in part, IGF-1-mediated signaling. However, both GHRP-6 and biotin, as non-conjugated forms, did not show IGF-1 stimulating activity. To explore binding molecules specific for GHRP-6-biotin conjugate compounds, MADLI-TOF analysis after coprecipitation was performed (Fig. 4). Among the proteins identified was desmin, a muscle-specific protein and a key subunit of the intermediate filament in cardiac, skeletal, and smooth muscle. It has been suggested that desmin plays a critical role in the maintenance of the structural and mechanical integrity of the contractile apparatus in muscle tissue (25). Skeletal muscle of desmin knockout mice shows higher susceptibility to mechanical injury (26) and inhibiting desmin protein expression via anti-sense RNA treatment resulted in a blockade of myotube formation in cultured myoblast $\mathrm{C} 2 \mathrm{C} 12$ cells (27). In a skeletal muscle atrophy model, desmin is also a target molecule for muscle-specific ubiquitin ligase, Atrogin1, and tripartite motif (RING, B-box, coiled-coil)containing Trim32 $(28,29)$. These results suggest that the GHRP-6-biotin conjugate compound might prevent the degradation of desmin by ubiquitin ligases through direct binding. While further investigation is needed to clarify the role of the GHRP-6-biotin conjugate and its effects on myogenesis, our results suggest that the newly synthesized GHRP-6-biotin conjugate has stimulatory effects on myogenesis, at least in part, through up-regulating collagen type I and IGF-1 expression.

\section{MATERIALS AND METHODS}

\section{Cell culture and antibodies}

The mouse myoblast cell line $\mathrm{C} 2 \mathrm{C} 12$ was obtained from the American Type Culture Collection (ATCC; Manassas, VA, USA) and cultured in Dulbecco's modified Eagle's medium (DMEM, Gibco, Invitrogen, Grand Island, NY, USA) supplemented with $1 \%$ penicillin/streptomycin and $10 \%$ FBS in a $5 \%$ $\mathrm{CO}_{2}$ incubator at $37^{\circ} \mathrm{C}$ according to a previously described method (30). Briefly, C2C12 myoblasts at $90-100 \%$ confluency were differentiated into myotubes by growth medium with differentiation medium (DMEM supplemented with $1 \%$ penicillin/streptomycin and 2\% horse serum). Every $48 \mathrm{~h}$, the differentiation medium of the myotubes was replaced.

Anti-myogenin and caveolin-3 antibodies were purchased from BD Transduction Laboratories (San Jose, CA, USA), and anti-beta-actin and alpha-actin antibodies were from Pierce 
(Thermo LabSystem, Waltham, MA, USA). Anti-myosin heavy chain antibody was from Sigma-Aldrich (St. Louis, MO, USA) and anti-MG53 antibody was provided by Dr. YG Ko (Korea University, Seoul, Korea).

\section{Materials}

GHRP-6 was synthesized by Anygen Co., Ltd. (Gwangju, Korea) and biotin and other reagents used for the conjugation were purchased from Sigma-Aldrich. The GHRP-6-biotin conjugate compound was synthesized by a FMOC solid-phase peptide synthesis method using a glass reactor vessel. The reaction mixture was purified by reverse-phase high-performance liquid chromatography (HPLC) using a Vydac Everest C18 column. Elution was carried out with a water-acetonitrile linear gradient $(10-75 \%(\mathrm{v} / \mathrm{v})$ acetonitrile) containing $0.1 \%$ $(\mathrm{v} / \mathrm{v})$ trifluoroacetic acid. The molecular weight of the purified compound was confirmed by LC/MS.

\section{Protein measurements and enzyme activity assay}

To measure protein expression and enzyme activity in vitro, $\mathrm{C} 2 \mathrm{C} 12$ myoblast cells were treated with test compounds in differentiation media for $24 \mathrm{~h}$. The expressions of IGF-1 and collagen 1 in the culture medium were measured using an IGF-1 ELISA kit (Abcam, Cambridge, MA, USA) and a collagen type I ELISA kit (Chondrex Inc., Redmond, WA, USA), respectively, according to the manufacturers' instructions. For measuring the energy-metabolism related enzyme activities and metabolites, cell were incubated with serum-free medium containing test samples for $16 \mathrm{~h}$. After washing with ice-cold PBS three times, cells were collected and lysed with assay buffer. Cell lysates were centrifuged $(12,000 \mathrm{~g}, 10 \mathrm{~min})$. The supernatant was collected and creatine kinase (CK) and lactate dehydrogenase $(\mathrm{LDH})$ activities were measured by appropriate activity assay kits (Abcam), after filtering the supernatant with a $10 \mathrm{kDa}$ spin column (Abcam). ATP and lactate concentrations in the supernatant were also measured using an ATP assay kit and a lactate assay kit (Abcam), respectively.

\section{Western blotting and silver staining}

Western blotting was performed as described previously (31). Briefly, the proteins in the whole cell lysates were separated on SDS-polyacrylamide gels and transferred to a PVDF membrane. The antigens were visualized by sequential treatment with specific primary antibodies, HRP-conjugated secondary antibodies, and an enhanced chemiluminescence substrate kit (Thermo Scientific).

For silver staining, $\mathrm{C} 2 \mathrm{C} 12$ cells were incubated with test compound for $1 \mathrm{~h}$ at $37^{\circ} \mathrm{C}$ and washed three times with icecold PBS. Then, cells were treated with the cross-linker, DSS (Thermo Scientific) for 15 min and washed twice with PBS $(\mathrm{pH}$ 8.0). Whole cell lysates $(500 \mu \mathrm{g})$ were incubated with streptavidin-agarose beads for $18 \mathrm{~h}$ at $4^{\circ} \mathrm{C}$. The precipitates were resolved by SDS-PAGE and the analytical gels were stained using the PlusOne silver staining kit (Thermo Scientific) accord- ing to the manufacturer's protocol.

\section{Binding assay by sandwich ELISA}

Briefly, desmin protein in C2C12 cell lysates was captured by protein-specific antibodies (Antibodies Online, Atlanta, GA, USA) and then the GHRP-6-biotin conjugate was added in a dose-dependent manner. The bound complex was detected with avidin-conjugated HRP and a colorimetric reaction.

\section{Matrix-assisted laser desorption/ionization time of flight (MALDI-TOF) analysis}

To search the binding proteins of the test sample, MALDI-TOF analysis was performed. Briefly, proteins were subjected to in-gel trypsin digestion and excised gel spots were destained with $100 \mu \mathrm{l}$ of destaining solution $(50 \%$ methanol/distilled water) with shaking for $5 \mathrm{~min}$. After removal of the solution, gel spots were incubated with $200 \mathrm{mM}$ ammonium bicarbonate solution for $20 \mathrm{~min}$. The gel pieces were dehydrated with 100 $\mu \mathrm{l}$ of acetonitrile and dried in a vacuum centrifuge. Then, 50 $\mu \mathrm{l}$ of $10 \mathrm{mM}$ DTT in $0.1 \mathrm{M}$ ammonium bicarbonate solution was added to the residue and incubated for $30 \mathrm{~min}$ at $56^{\circ} \mathrm{C}$ with shaking. After spin down, the supernatant was removed and acetonitrile was added to shrink the protein. After adding $50 \mu \mathrm{L}$ of $55 \mathrm{mM}$ of iodoacetamide in $0.1 \mathrm{M}$ ammonium bicarbonate solution, the mixture was incubated for $20 \mathrm{~min}$ in the dark. Washing with acetonitrile and $0.1 \mathrm{M} \mathrm{ABC}$ solution treatment was performed three times. The dried gel pieces were rehydrated with $20 \mu \mathrm{l}$ of $50 \mathrm{mM}$ ammonium bicarbonate solution containing modified trypsin (Promega, Madison, WI) for $45 \mathrm{~min}$ on ice. After removal of the solution, $30 \mu \mathrm{l}$ of $50 \mathrm{mM}$ ammonium bicarbonate solution was added and the digestion reaction was performed overnight at $37^{\circ} \mathrm{C}$. The peptide solution was desalted using a ZipTip C18 column and analyzed using an UltraFlex III MALDI-TOF/TOF system (Bruker Corp., Fremont, CA, USA).

\section{ACKNOWLEDGEMENTS}

We appreciate technical advice in preparing the manuscript from Mr. Josh Shaw at Mission Athletecare.

\section{REFERENCES}

1. Makrantonaki E, Schonknecht $P$, Hossini AM et al (2010) Skin and brain age together: The role of hormones in the ageing process. Exp Gerontol 45, 801-813

2. Zouboulis CC and Makrantonaki E (2012) Hormonal therapy of intrinsic aging. Rejuvenation Res 15, 302-312

3. DeVita RJ (1997) Small molecule mimetics of GHRP-6. Expert Opin Investig Drugs 6, 1839-1843

4. Micic D, Casabiell X, Gualillo O, Pombo M, Dieguez C and Casanueva FF (1999) Growth hormone secretagogues: the clinical future. Horm Res 51 Suppl 3, 29-33

5. Makrantonaki E, Zouboulis CC and German National Genome Research N (2007) The skin as a mirror of the ag- 
ing process in the human organism-state of the art and results of the aging research in the German National Genome Research Network 2 (NGFN-2). Exp Gerontol 42, 879-886

6. Florini JR, Ewton DZ and Coolican SA (1996) Growth hormone and the insulin-like growth factor system in myogenesis. Endocr Rev 17, 481-517

7. Yi JS, Park JS, Ham YM et al (2013) MG53-induced IRS-1 ubiquitination negatively regulates skeletal myogenesis and insulin signalling. Nat Commun 4, 2354

8. Paneda C, Arroba Al, Frago LM et al (2003) Growth hormone-releasing peptide- 6 inhibits cerebellar cell death in aged rats. Neuroreport 14, 1633-1635

9. Smith RG (2005) Development of growth hormone secretagogues. Endocr Rev 26, 346-360

10. Granado M, Garcia-Caceres C, Tuda M, Frago LM, Chowen JA and Argente J (2011) Insulin and growth hormone-releasing peptide-6 (GHRP-6) have differential beneficial effects on cell turnover in the pituitary, hypothalamus and cerebellum of streptozotocin (STZ)-induced diabetic rats. Mol Cell Endocrinol 337, 101-113

11. Berlanga J, Cibrian D, Guevara L et al (2007) Growth-hormone-releasing peptide 6 (GHRP6) prevents oxidant cytotoxicity and reduces myocardial necrosis in a model of acute myocardial infarction. Clin Sci (Lond) 112, 241-250

12. Pontiroli AE (1998) Peptide hormones: Review of current and emerging uses by nasal delivery. Adv Drug Deliv Rev 29, 81-87

13. Fleisher D, Niemiec SM, Oh CK, Hu Z, Ramachandran C and Weiner N (1995) Topical delivery of growth hormone releasing peptide using liposomal systems: an in vitro study using hairless mouse skin. Life Sci 57, 1293-1297

14. Charge SB and Rudnicki MA (2004) Cellular and molecular regulation of muscle regeneration. Physiol Rev 84, 209-238

15. Smith CK, 2nd, Janney MJ and Allen RE (1994) Temporal expression of myogenic regulatory genes during activation, proliferation, and differentiation of rat skeletal muscle satellite cells. J Cell Physiol 159, 379-385

16. Asakura A, Komaki M and Rudnicki M (2001) Muscle satellite cells are multipotential stem cells that exhibit myogenic, osteogenic, and adipogenic differentiation. Differentiation 68, 245-253

17. Florini JR, Ewton DZ and Magri KA (1991) Hormones, growth factors, and myogenic differentiation. Annu Rev Physiol 53, 201-216

18. Lee CS, Yi JS, Jung SY et al (2010) TRIM72 negatively regulates myogenesis via targeting insulin receptor substrate-1. Cell Death Differ 17, 1254-1265

19. Frago LM, Paneda C, Dickson SL, Hewson AK, Argente J and Chowen JA (2002) Growth hormone (GH) and GH-re- leasing peptide- 6 increase brain insulin-like growth factor-l expression and activate intracellular signaling pathways involved in neuroprotection. Endocrinology 143, 4113-4122

20. Frago LM, Paneda C, Argente J and Chowen JA (2005) Growth hormone-releasing peptide-6 increases insulinlike growth factor-I mRNA levels and activates Akt in RCA-6 cells as a model of neuropeptide $\mathrm{Y}$ neurones. J Neuroendocrinol 17, 701-710

21. Zhou S, Salisbury J, Preedy VR and Emery PW (2013) Increased collagen synthesis rate during wound healing in muscle. PLoS One 8, e58324

22. Bonaldo P, Braghetta P, Zanetti M, Piccolo S, Volpin D and Bressan GM (1998) Collagen VI deficiency induces early onset myopathy in the mouse: an animal model for Bethlem myopathy. Hum Mol Genet 7, 2135-2140

23. Takano H, Komuro I, Oka T et al (1998) The Rho family G proteins play a critical role in muscle differentiation. Mol Cell Biol 18, 1580-1589

24. Schwander M, Leu M, Stumm M et al (2003) Beta1 integrins regulate myoblast fusion and sarcomere assembly. Dev Cell 4, 673-685

25. Paulin D and Li Z (2004) Desmin: a major intermediate filament protein essential for the structural integrity and function of muscle. Exp Cell Res 301, 1-7

26. Li Z, Mericskay M, Agbulut O et al (1997) Desmin is essential for the tensile strength and integrity of myofibrils but not for myogenic commitment, differentiation, and fusion of skeletal muscle. J Cell Biol 139, 129-144

27. Li H, Choudhary SK, Milner DJ, Munir MI, Kuisk IR and Capetanaki Y (1994) Inhibition of desmin expression blocks myoblast fusion and interferes with the myogenic regulators MyoD and myogenin. J Cell Biol 124, 827-841

28. Lokireddy S, Wijesoma IW, Sze SK, McFarlane C, Kambadur R and Sharma M (2012) Identification of atrogin-1-targeted proteins during the myostatin-induced skeletal muscle wasting. Am J Physiol Cell Physiol 303, C512529

29. Cohen S, Zhai B, Gygi SP and Goldberg AL (2012) Ubiquitylation by Trim32 causes coupled loss of desmin, Z-bands, and thin filaments in muscle atrophy. J Cell Biol 198, 575-589

30. Hong J, Kim BW, Choo HJ et al (2014) Mitochondrial complex I deficiency enhances skeletal myogenesis but impairs insulin signaling through SIRT1 inactivation. J Biol Chem 289, 20012-20025

31. Kim BW, Lee JW, Choo HJ et al (2010) Mitochondrial oxidative phosphorylation system is recruited to detergent-resistant lipid rafts during myogenesis. Proteomics 10, 24982515 